Accepted refereed manuscript of:

Hart KA, Gray T \& Stead SM (2013) Consumptive versus non-consumptive use of sea turtles? Stakeholder perceptions about sustainable use in three communities near Cahuita National Park, Costa Rica. Marine Policy, 42, pp. 236-244.

DOI: https://doi.org/10.1016/j.marpol.2013.03.008

(C) 2013, Elsevier. Licensed under the Creative Commons AttributionNonCommercial-NoDerivatives 4.0 International http://creativecommons.org/licenses/by-nc-nd/4.0/ 


\title{
Consumptive versus non-consumptive use of sea turtles? Stakeholder perceptions about sustainable use in three communities near Cahuita National Park, Costa Rica.
}

\author{
Katharine Hart, Tim Gray, and Selina M. Stead \\ Newcastle University
}

\begin{abstract}
Declining populations of sea turtles has heightened controversy between two contrasting strategies for their sustainable management: consumptive use versus non-consumptive use. This study investigates perceptions held by individuals in three communities bordering a marine protected area in Costa Rica about consumptive and non-consumptive use of sea turtles on nesting beaches to determine how best to achieve sustainable management of the species. Face-to-face interviews ( $n=48$ community members and $n=8$ key informants) were conducted in 3 communities (Cahuita Town, Hone Creek, and Playa Negra) during April and May 2009. The research found that in each community, residents' perceptions about consumptive and non-consumptive use were divided into four categories: norm-activated pro- and anti- environmentalism; and rationally self-interested pro- and anti- environmentalism. Given this perceptual diversity, it seems clear that no single management strategy would work successfully across all three communities, but that customised management measures were required to manage sea turtle populations in each area. The wider implication of this study is that there is no simple panacea for dealing with declining populations of sea turtles: each situation is sui generis, requiring measures tailored exclusively to its particular circumstances.
\end{abstract}

Key words: sea turtles; poaching; marine protected areas; conservation; Costa Rica

\section{Introduction}

Around the world sea turtles have become endangered by human activity, especially hunting for shell and meat, harvesting of eggs, and incidental capture in fishing gear [1]. All seven species are reported as declining, and six of them are classified between critically endangered and vulnerable on the IUCN Red List [hawksbill, leatherback and kemp's ridley = critically endangered; green and loggerhead = endangered; olive ridley = vulnerable; and flatback = insufficient data] [2]. Use of sea turtles occurs in both consumptive and nonconsumptive forms. Consumptive use entails permanent removal from the environment of eggs, or of adults or sub-adults for their meat and/or shells. Sometimes consumptive use is approved by governments: for example, legalized egg harvesting projects occur in Costa Rica [3][4][5][6], Nicaragua [6] and Suriname [7]. Nonconsumptive use of sea turtles is entailed in ecotourism, which makes use of wildlife, in that tourists pay to see turtles, but does not result in direct removal of individuals or their products from the environment. Ecotourism, which is growing in both developing countries [8][9][10][11] and developed countries [12], is defined as: "environmentally responsible travel and visitation to relatively undisturbed natural areas, in order to enjoy and appreciate nature (and any accompanying cultural features - both past and present) that promotes conservation, has low visitor impact, and provides for beneficially active socio-economic involvement of local populations" [13]. However, non-consumptive use can still have damaging effects on the sea turtle population [9].

Although use of sea turtle eggs is sometimes permitted, sea turtles are formally protected from consumptive use by national and international legislation [14]. However, illegal hunting and egg removal from nesting beaches often referred to as poaching [15] - is a serious threat to the conservation of populations [16][17]. Consequently, to protect sea turtles, it is crucial to understand the source of such threats. Individuals' motives for poaching are varied, and differ from place to place. Wood [16] found that poaching within a marine protected area in the Seychelles was primarily driven by economic factors; while Hampshire et al [18] reported that where resources and employment opportunities are limited, the main reason for poaching was for subsistence. Jagers et al [19] claimed that there were four main reasons why fishers do or do not comply with regulations: (a) self-interest; (b) moral compulsion; (c) peer pressure; and (d) fairness of the regulations. Muth \& Bowe [20] suggested other motives, including commercial gain, recreational pursuit, the desire to exercise traditional rights and rebellious behaviour. These motives are not mutually exclusive, and an individual poacher may be driven by more than one of them simultaneously, or by different motives at different times of his/her life [21].

As tourism in Costa Rica has increased, the importance of sea turtles has shifted from use as a consumptive, nutritional resource, to a non-consumptive resource attracting large numbers of visitors to otherwise unvisited locations. However, local individuals who are unable to become involved in the tourism industry or derive any benefits from it may resort to poaching as a source of income, particularly if there remains a demand for prohibited products. Little research has focussed on understanding the motives which lead individuals to poach 
sea turtle products, but if management is to conserve sea turtle populations, it is necessary to investigate these motives in detail so that more effective measures can be devised. This study aims to help fill this gap by examining the drivers behind sea turtle egg poaching on the Caribbean coast of Costa Rica. The objectives of this study are to investigate perceptions of sea turtles and their value in three communities surrounding Cahuita National Park; to identify the motivations of sea turtle poachers in these communities; and to suggest more effective ways of reducing poaching. In section 2 , the theoretical framework that informs this study is outlined. In section 3, the research methods employed in the study are explained. In section 4, the results of the fieldwork are presented. In section 5, these results are discussed, and in the concluding section 6 , there is a summary of the paper's findings and their wider implications.

\section{Theoretical framework}

Bamberg \& Moser [22, p15] reviewed "the theoretical models most frequently applied for explaining proenvironmental behaviour" and concluded that "Researchers who view environmental behaviour primarily as pro-socially motivated often use the norm-activation model...as theoretical framework, whereas researchers who view self-interest as the more important motive often rely on rational choice methods like the theory of planned behaviour". Accordingly, these two contrasting theories of compliant or pro-environmental behaviour - 1) the norm-activation model (NAM); and 2) the theory of planned behaviour (TPB) - are used to guide this study.

\subsection{Norm-Activation Model (NAM)}

The norm-activation model (NAM) attributes pro-environmental behaviour to moral norms or values [23]. Schwartz [24] originated the theory that moral norms explain altruistic behaviour [25]. Bamberg \& Moser [22, p15] explain that Schwartz "conceived moral norms as feelings of strong moral obligations that people experienced for themselves to engage in pro-social behaviour", adding that "In line with this model several primary studies provide evidence that moral norms contribute to an explanation of pro-environmental behaviours like energy conservation...recycling... and pro-environmental buying". Stern's contribution to the development of the theory includes awareness of the adverse normative consequences of non-environmental behaviour [26][27].

\subsection{Theory of Planned Behaviour (TPB)}

The theory of planned behaviour (TPB) attributes pro-environmental behaviour to rational intentions: "One central assumption of the TPB is that intention is the only direct psychological determinant of behaviour" [23, $p$ 191). Intention is itself the result of a rational calculation of self-interest: "Intention is viewed as a summary of all the pros and cons a person takes into account when deliberately reasoning whether he/she should perform a behavioural option or not" [23, p191]. Ajzen [28] originated TPB, and according to Bamberg \& Moser [22, p16), “Ajzen's TPB is based on a more hedonistic model of human beings. It assumes that people are motivated to avoid punishments and to seek rewards. According to this model, decision-making is guided by a rational evaluation of behavioural consequences".

In what follows, we will find that some Costa Rican respondents appeared to be motivated in their proenvironmental behaviour by moral norms (NAM); others by self-interest (TPB); but most by a combination of both. This seems to confirm Bamberg \& Moser [22, p15-16] assertion that "Pro-environmental behaviour is probably best viewed as a mixture of self-interest... and of concern for other people, the next generation, other species, or whole eco-systems...[and] it is suggested to combine both theoretical frameworks". Our own interpretation is that TPB is potentially the stronger motivating force for pro-environmental behaviour, but that unless the right (economic) incentives are in place, it may lapse into anti-environmental behaviour. NAM is less likely to be manifested in anti-environmental behaviour, but it is a weaker pro-environmental motivating force than TPB, and may fail to prevent TPB from lapsing into anti-environmental behaviour.

\section{Research methods}

\subsection{Study site}

Cahuita National Park, located in the province of Limón on the Caribbean coast of Costa Rica, was selected as the site for this study (see Figure 1). The park is divided into two sectors: Playa Blanca, which is administered by the Management Committee consisting of Cahuita community members and government representatives; and the rest of the park which is administered by the National Parks Service. However, no management plan exists for the park [29], and the objectives of the park are not explicitly defined. The sea turtle conservation project in 
Cahuita was established in 1997 by the Wider Caribbean Sea Turtle Conservation Network (WIDECAST), a non-governmental organisation (NGO) nationally and internationally involved in sea turtle conservation. WIDECAST has hosted similar projects at other locations in Costa Rica, including Gandoca (south of Cahuita), which is widely regarded as successful in terms of conservation and community satisfaction - ideal ecotourism. [2][4][5][30]. Three communities (see Figure 1) surrounding Cahuita National Park - Cahuita Town, Hone Creek, and Playa Negra - were selected as interview locations in order to compare local perceptions of sea turtles and their use by residents. A scoping study was conducted with community members in Gandoca village (located to the south of the study site) in order to pilot potential questions and trial interview techniques.

\subsection{Data collection}

During April and May 2009, open-ended questionnaires were conducted with key informants to highlight key issues of relevance to this study. Six key informant interviews were carried out with members of WIDECAST, scientific researchers and park rangers. Forty-eight survey interviews with community members were conducted face-to-face using semi-structured questionnaires in the three study sites: Cahuita Town $(n=14)$, Hone Creek $(n=24)$, and Playa Negra $(n=10)$. Survey interviewees were selected by means of random sampling and convenience sampling techniques, and the interviews were carried out on an individual basis, taking between 30 and 90 minutes per interview. Each survey interview was conducted in Spanish with the assistance of a translator, or in English where appropriate, and the questions were designed to collect both quantitative and qualitative data regarding stakeholders' perceptions of sea turtle populations, their value to the community, and their use. Survey interviewees were also asked to identify the boundaries of the national park on a map to assess local knowledge across demographic groups.

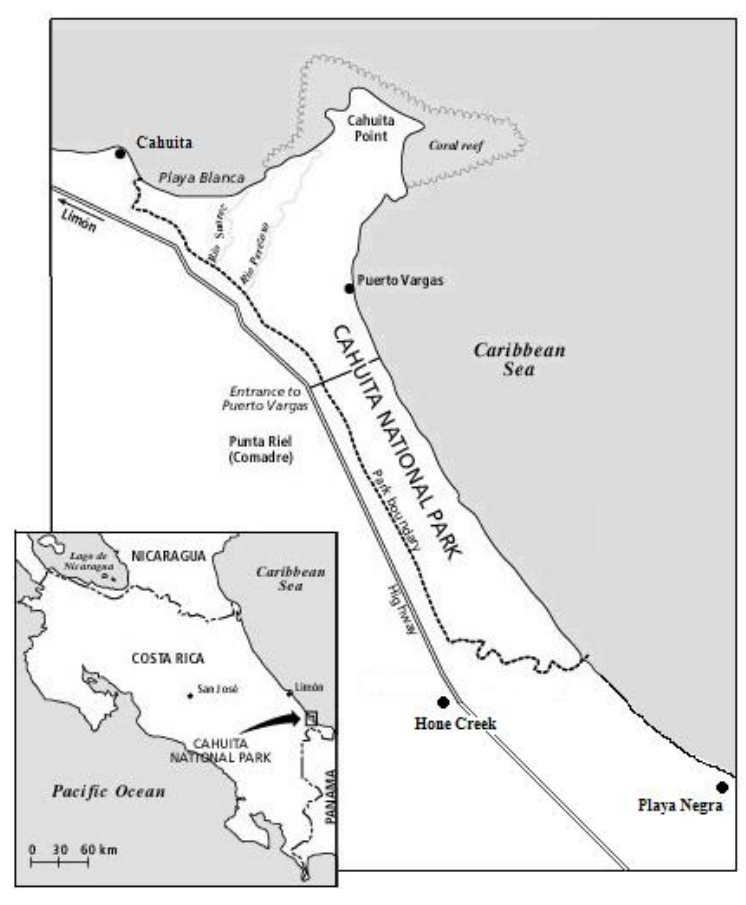

Figure 1: Cahuita National Park with the three study sites located: Cahuita Town, Hone Creek, and Playa Negra (Source Buckles, D. 1999)

\subsection{Data Analysis}

The survey questionnaire used dichotomous variables, Likert scales, and free response questions. All responses were translated into English where necessary. Qualitative data was analysed using discourse analysis in order to identify common themes and their differing significance to each demographic group. The statistical software program SPSS Version 17.0 was used for analysis of quantitative data, and responses were coded at point of entry. Spearman's Rho correlation analyses were used to investigate relationships between variables. To compare responses by individuals and communities to Likert-scale questions, Kruskal-Wallis tests were used. 
Two-way Chi-square tests were used to analyse differences in responses to dichotomous and free response questions, where $\mathrm{p}<0.05$ results were deemed to be significant. The qualitative results from the free-response questions provide the context through which to interpret the results of the statistical analyses.

\section{Results}

The results of the fieldwork are presented in seven parts: community socio-economic characteristics; awareness of sea turtle conservation projects; importance of sea turtles; norm-activated motivation; rational self-interested motivation; perceptions of governance effectiveness; and prescriptions for the future.

\subsection{Community socio-economic characteristics}

The three communities varied considerably in their economic and social characteristics. Features of the communities such as occupational profile and community cohesion were assessed in order to identify relationships between the communities' structures and their residents' perceptions of sea turtles, their use, and their importance (Table 1). The primary occupation of community members in Playa Negra and Hone Creek informal economic activity - highlighted the importance of opportunistic employment. In Cahuita Town, where the primary occupation was tourism-based, one respondent stated that "95\% of this community is involved in tourism, either directly or indirectly", explaining that while cabina and restaurant owners received direct benefits from tourism, fishermen benefitted indirectly through sales of fish to restaurants.

\begin{tabular}{|c|c|c|c|}
\hline \multirow{2}{*}{ Characteristic } & \multicolumn{3}{|c|}{ Community } \\
\cline { 2 - 4 } & Cahuita Town & Hone Creek & Playa Negra \\
\hline Population & Approx. 560 & Approx. 800 & Approx 250 \\
\hline Primary occupation & Tourism sector & Informal economic activity & Informal economic \\
& & & 0 \\
\hline Community Groups & 8 & 2 & 0 \\
\hline
\end{tabular}

Table 1: Characteristics of communities surveyed during April and May 2009.

Community cohesion was measured by the number of community groups through which information exchange and communication occurred. Cahuita Town had the highest level of community cohesion, with eight community groups identified by respondents. Social cohesion in Hone Creek (HC) was lower than in Cahuita Town (CT) - "People here are very apart" (HC respondent) - but higher than in Playa Negra (PN), where no community groups were identified. One $\mathrm{HC}$ respondent said that its two community groups "Serve the community and look for the problems and needs", though others were more critical - "They don't do anything"; "The only thing they do is make politics"; "They are not very serious - they are just looking for money for themselves"; "They need to open up more...They need to involve more people, they are very closed"; "They need to bring other people in" - and one suggested that "Institutions from outside should help because the people around here are very poor". The lowest level of community cohesion was found in Playa Negra because it had a highly transient population and no community groups. One PN respondent observed that "people here are very different to the people in Cahuita"; but others lamented the lack of community cohesion: "need a community group here, it would be nice. People here are very independent at the moment"; "Because I am part of the community, as is everybody else...I should be involved in the decisions"; "If it is something good for the community, it is important that you cooperate"; "A whole lot of them involved it is good, but if only a few of them is involved it doesn't work".

\subsection{Awareness of the sea turtle conservation project}

Respondents were asked questions about their awareness of the sea turtle conservation project. On the existence, purpose, and success of the sea turtle conservation project in Cahuita National Park, 42.8\% ( $\mathrm{n}=14)$ of respondents in Cahuita Town, 87.0\% $(n=23)$ in Hone Creek, and 90.0\% $(n=10)$ in Playa Negra stated that they were unaware of the project, with some adamant that "there is no project". A significant difference in awareness of the project was identified between these locations using a 2 -way Chi-Square test $\left(\chi_{46}^{2}=10.114, d . f=2, p<0.05\right)$ - respondents in Cahuita had much greater awareness of the project than those in either Hone Creek or Playa Negra. By contrast, on awareness of the existence of the Cahuita National Park itself, no significant differences were identified in responses between communities: $80.4 \%(n=46)$ of all respondents were aware of its existence. However, when asked to indicate the boundaries of the national park on a map, the majority of all respondents $(67.7 \%)$ were unable to identify them correctly, and only $32.3 \%(n=31)$ correctly identified them. Interestingly, park boundaries were incorrectly identified by a park ranger. 


\subsection{Importance of sea turtles}

Respondents were asked how important sea turtles were to their communities and to themselves, and why. On how important sea turtles were perceived to their communities, across the three locations $43.5 \%(n=48)$ perceived sea turtles as very important; $34.8 \%$ important; $19.6 \%$ fairly important; and $2.1 \%$ unimportant (see Table 2). When asked about their importance to themselves, $62.5 \%(n=46)$ perceived sea turtles as very important; $20.8 \%$ important; $12.5 \%$ fairly important; and $4.2 \%$ unimportant. Correlations between responses by community for importance of sea turtles to the community and to the individual were found to be significant using a Spearman's Rho, $\mathrm{r}_{46}=0.295, \mathrm{p}<0.05$. On the reasons why sea turtles were important to them, the difference in responses between the communities was not significant ( 2 -way Chi-Square $\chi^{2}=18.171$, d.f. $=12$, $\mathrm{p}>0.05)$. In Cahuita Town, tourism was reported as the primary basis of the value of sea turtles by $30.8 \%(n=14)$ of respondents, whereas in both Hone Creek and Playa Negra the intrinsic value of sea turtles was cited as the most important factor $-52.4 \%(n=24)$ and $30.0 \%(n=10)$ respectively.

\begin{tabular}{|c|c|c|c|c|}
\hline \multirow{2}{*}{ Community } & \multicolumn{3}{|c|}{ Importance of Sea Turtles to each community (\%) } \\
\cline { 2 - 5 } & Very Important & Important & Fairly Important & Unimportant \\
\hline $\begin{array}{c}\text { Cahuita Town } \\
(\mathrm{n}=12)\end{array}$ & 33.3 & 33.3 & 33.3 & 0.0 \\
\hline $\begin{array}{c}\text { Hone Creek } \\
(\mathrm{n}=24)\end{array}$ & 50.0 & 33.3 & 12.5 & 0.2 \\
\hline $\begin{array}{c}\text { Playa Negra } \\
(\mathrm{n}=10)\end{array}$ & 40.0 & 40.0 & 20.0 & 2.1 \\
\hline $\begin{array}{c}\text { All Communities } \\
(\mathrm{n}=46)\end{array}$ & 41.7 & 33.3 & 18.8 & 0.0 \\
\hline Statistics & \multicolumn{3}{|c|}{ Chi-Square, $\chi^{2} 46=3.339$, d.f. $=6, \mathrm{p}>0.05$} \\
\hline
\end{tabular}

Table 2: Reasons given by interviewees why turtles are important to each of the three surveyed communities.

\subsection{Norm-activated motivation}

Respondents were asked whether they were influenced by norms or values in their views on sea turtle use. When asked if the use of sea turtles was morally acceptable, there was no significant difference in responses between communities: $70.2 \%(n=47)$ of all respondents held that consumptive use of sea turtles was not morally acceptable, while the other $29.8 \%$ believed that consumptive use was morally acceptable. To ascertain their socio-cultural beliefs about sea turtles, respondents were asked about the traditional use of sea turtles. Of the respondents questioned, $96 \%(n=25)$ reported consumption of sea turtle eggs and meat as a traditional practice in these communities, indicating the important status of the sea turtle within local culture. Statements made by respondents revealed a range of norm-activated views that can be divided into two sets: 1) pro-environmental; and 2) anti-environmental:

\subsubsection{NORM-ACTIVATED PRO-ENVIRONMENTALISM (NON-CONSUMPTIVE USE)}

Norms that activated pro-environmental perceptions included personal, moral, aesthetic, ecological, social, legal, and cultural norms. Examples of personal norms included personal responsibility: "If I know who is taking the eggs then it is my responsibility to report them to the right people"; "I used to cook it but now we have to have more responsibility"; "I worry for their protection" (HC respondents); personal feelings: "They are important to me in the same way as my dogs are"; "Because I like wildlife"; "They are nice animals"; "It is nice to appreciate them with sons and grandsons so that they can enjoy it too" (HC respondents); "Because I like to see them... when snorkelling and diving it is good to see them"; "I am sure that my sons and grandsons will want to see the turtles" (PN respondents); and self-restraint: "People used to take the eggs but not all of them - they never took all the eggs so that they could still reproduce"; "We can't kill them indiscriminately" (CT respondents). Examples of moral norms include: "They're part of the nature of the sea"; "We need to respect them"; "We have to conserve and take care of them so they don't go extinct" (CT respondents); "They are something natural and they are supposed to be there"; "It is important to protect turtles as it is for all nature"; "They are part of life and the planet"; "They have a right to live just like us"; "We have to respect the nature"; "They are part of the marine fauna... We should leave them there"; "Don't take them from the ocean...They are 
supposed to stay where they belong"; "People that kill them are exterminating them" (HC respondents); "We have to respect them just like we respect humans"; "It is important because it is a creature...Look on them as a part of nature"; "They should be free... Would you like it? Well, the turtle doesn't either...It's free"; "We're not here to destroy... He put everything here for us but you don't kill what you don't need" (PN respondents). Examples of aesthetic norms include: "They decorate the oceans and they are pretty and sweet" (CT respondent). "They are pretty"; "They are very important because they are beautiful animals and we should take care of them"; "They are interesting animals"; "you can appreciate the things that are pretty and leave them there" (HC respondents); "They are very beautiful and bring people to the area"; "It is important to conserve the beautiful things along this coast" (PN respondents). Examples of ecological norms include: "It is very important for the ecosystem"; "For the ecosystem it is important to keep them alive". "They keep the water clean and clean up the sea"; "people need to understand we are in a chain of life. If we start eliminating things we go too. We are just a link in the chain"; "If we don't protect them and we destroy them, soon there won't be anything left"; "It is important to protect the small things so you can prevent any danger of extinction" (CT respondents); "There is a chain-as we lose the turtles we will lose the next resource"; "We have to leave them because they are getting scarce"; "I think that people should look for something else to do to survive because the turtle is facing extinction" (HC respondents); "There aren't very many left"; "If you don't take care of the animals they will go extinct" (PN respondents). Examples of social norms include the fact that the appeal of "easy money" (CT respondent) diminished as the peer pressure to comply with conservation regulations rose [27]; and the inculcation of environmental values by the community: "Students go to Gandoca...The people there teach them all about where they lay and how to conserve them... Then the children can keep that feeling inside as they grow up" (HC respondent). Examples of legal norms included; "I heard several times that it is prohibited by the law to collect sea turtles"; "people can't take the turtles"; "You can't catch turtle... you can go to prison"; "Lots of things you used to do before you cannot do now"; "We have to have rules, because without those rules there would be no control of the animals...You could go and take what you want, so there needs to be rules" (CT respondents); "If it is legal then yes... But if it isn't then no"; "The government is stopping it now so it's harder...People used to walk the street selling the meat in the past...But now you can go to jail for doing that" (HC respondents). Examples of cultural norms include: "They are important not only to humanity...God makes reptiles"; "It is a creature from God"; "The Bible makes the distinction between clean and unclean animals - humans should not eat reptiles"; "You shouldn't eat anything with a shell"; "They have a historical importance here"; "My culture states that it should stay there unmolested" (CT respondents); " $a$ turtle is a creation of God and so we should take care of them just as other animals"; "We are not supposed to eat them... Turtle meat can make you sick" (HC respondents); "For me it is very important to keep them because it is an animal God sent for us" (PN respondent).

\subsubsection{NORM-ACTIVATED ANTI-ENVIRONMENTALISM (CONSUMPTIVE USE)}

Throughout Costa Rica consumption of sea turtles and their eggs is a long-practised socio-cultural norm, embedded in local tradition [29]. Respondents were keen to share information about traditions, stating "Through culture, I buy it once a year" (CT respondent); "People here have always used the turtles, earth, sea and the land...It is complicated and a cultural thing"; "it is part of the culture to use turtles, especially in Limon"; "In the past, people used to live on it...It was a way of life for subsistence" (HC respondents). Similar to a respondent reported by Bell et al. [15], one $\mathrm{HC}$ respondent was keen to distinguish between individuals who "poach" and locals who are partaking local cultural practice, explaining that "a San Jose man never eat no turtle. You should only eat what there is where you are". Similarly, PN respondents claimed that "If you live here and you are hungry you should be able to eat them...You shouldn't sell the turtle but it's OK to catch and eat it for yourself"; "The bible says thou shall not kill, but also that you should kill to eat...It depends on the intention...So we eat off the turtle to survive"; "They have a right to live as we do...They are one of God's animals but the good book says you have to live and eat as well...You kill to eat...If you have to eat you can kill a turtle and you will eat"; "They're there to eat...God provides these things for us to eat...Eat until your belly is full"; "Do I think it's good? Yes...It's food, it puts a plate on the table if you are hungry"; "You should let people...do what they want... When Jesus was here, nobody had restrictions...The Earth is for all of us to enjoy".

\subsection{Rational self-interested motivation}

Respondents were asked whether people were influenced by rational self-interest in their views on sea turtle use. When respondents were asked why they believed individuals removed sea turtle eggs from local beaches, in Cahuita Town, the answer "easy money" was given by $60 \%$ of respondents; in Hone Creek, $83.3 \%$ of respondents stated that egg collection occurred in order to generate a subsistence income through sale of the 
eggs; and in Playa Negra, 50\% of respondents said it was "to eat" (see Table 3). When respondents were asked to identify

\begin{tabular}{|c|c|c|c|c|}
\hline \multirow{2}{*}{ Community } & \multicolumn{3}{|c|}{ Reasons for Poaching (\%) } \\
\cline { 2 - 5 } & $\begin{array}{c}\text { Money for } \\
\text { survival }\end{array}$ & Easy money & To eat & Lack of education \\
\hline $\begin{array}{c}\text { Cahuita Town } \\
(\mathrm{n}=5)\end{array}$ & 0 & 60 & 40 & 0 \\
\hline Hone Creek $(\mathrm{n}=12)$ & 83.3 & 16.7 & 0 & 25 \\
\hline Playa Negra $(\mathrm{n}=4)$ & 25 & 0 & 50 & 0 \\
\hline Statistics & \multicolumn{4}{|c|}{ Chi-Square, $\chi^{2}{ }_{21}=19.046$, d.f. $=6, \mathrm{p}<0.05$} \\
\hline
\end{tabular}

Table 3: Community members' perceptions about why people poach sea turtle eggs.

the primary use of sea turtles within their community, in Cahuita Town according to $71.4 \%$ of interviewees $(\mathrm{n}=14)$, the primary use was for tourism, attracting ecotourists to the area. By contrast, in Hone Creek and Playa Negra the consumption of sea turtle eggs and meat by local families, was stated to be the primary use by $52.1 \%$ $(n=21)$ and $87.5 \%(n=8)$ of residents respectively. This difference in use was statistically significant between communities ( 2 -way Chi-Square test: $\chi_{43}^{2}=27.440$, d.f. $=6, p<0.05$ ). When asked whether sea turtle eggs could be purchased, respondents indicated that they were difficult to buy in Cahuita Town $(76.9 \%, \mathrm{n}=14)$ but easy to buy in both Hone Creek $(68.2 \%, \mathrm{n}=22)$ and Playa Negra $(77.8 \%, \mathrm{n}=9)$ (see Figure 2 in Appendix 2). In Hone Creek "people like to buy them and so people still sell them", whereas in Cahuita "it is very hard because they are protected." This difference in availability was statistically significant ( 2 -way Chi-Square test $\chi^{2} 44=8.802, \mathrm{~d} . \mathrm{f}=2$, $\mathrm{p}<0.05)$. By contrast, there is no significant difference in the availability of sea turtle meat in the three communities: the majority of all respondents $(73.3 \% \mathrm{n}=45)$ reported that buying sea turtle meat was difficult; $13.3 \%$ stated that it was easy; and $13.3 \%$ said that "yes you can get it but not here". When asked if they were aware of a heavy demand for sea turtle products, there was no significant difference in responses between locations: most people interviewed did not think there was a heavy demand $(80.5 \%, \mathrm{n}=41)$. This suggests that while community members may buy and consume the products, it was not a high priority for them to do so. Statements made by respondents revealed a range of rational self-interested views that can be divided into two sets: 1) pro-environmental; and 2) anti-environmental:

\subsubsection{RATIONAL SELF-INTERESTED PRO-ENVIRONMENTALISM (NON-CONSUMPTIVE USE)}

Staff of the sea turtle conservation project did not consider consumptive use sustainable (Personal communication, 2009), a perception concurrent with that of many sea turtle experts [5]. In an area such as Cahuita National Park where sea turtle populations had become very low, the capacity for sustainable consumptive use of sea turtles was very limited, if possible at all. Although the 'shifting baseline' theory [31] suggests that conservationists are unsure of the historic numbers of turtles previously nesting on individual beaches, respondents at the study site were clear in their opinion that in the past "there were definitely more [turtles]", and that the population has "diminished greatly in this area". Indeed, one resident of Cahuita Town stated that turtles are "something of the past". Similarly, a PN respondent stated that "Here you used to see turtles all the time... But at the moment there aren't many left... The lights around here are driving them away". However, another PN respondent claimed that there were lots of turtles in Tortuguero and Limon: "The population is in Tortuguero, not here...And there are some in Limon...There's not so much here...There are hundreds and thousands there". As tourism became the primary source of income, consumption and sale of sea turtle products became less socially acceptable - 'eco-tourists' were unlikely to approve of consumptive use of sea turtles [5]. Many respondents in Hone Creek argued that since sea turtle conservation was important for tourism, tourism was good for turtle conservation: "They are important because they bring money into the community"; "We have got to take care of them so they can generate more tourism and work for the community"; "They are good for tourism ... because people come to see them and invest in the country...Tourism is good for the nature"; "Tourists from all over the world come here to see the turtles"; "They are more important to this community than other animals"; "I think that tourism conserves the turtles"; "Tourism is better for the turtles than eating the eggs and the meat". Similarly, PN respondents said that "Everything that is involved with tourism is good"; "tourism is OK...If they keep killing them it will...stop the tourism"; "If they use it for tourism it is good because it doesn't harm them"; "To eat, no...But for tourism, yes it is good...It's not good to take them... They should be free". Nevertheless, tourism had some negative impacts on sea turtles: "Tourism affects the life of the turtles as well"; "Lots of turtles when they feel like people are on top of them will go elsewhere to lay their eggs" (HC respondents); "The shell, I guess you could say, is used for tourism because the tourists buy the crafts" (PN respondent). 


\subsubsection{RATIONAL SELF-INTERESTED ANTI-ENVIRONMENTALISM (CONSUMPTIVE USE)}

One self-interested reason for consumption was the tastiness of turtle products: "The meat is delicious. Once you taste it you forget about all other meat"; "Turtle wing is the best, and it makes you really strong"; "It is nice and sticky with coconut or bananas" (CT respondents); "They make good soup" (HC respondent); "I eat turtle fin, back and everything... Without it I feel like I don't have any strength...It's not a thing you can eat everyday because it is very strong"; "You eat them with fresh chilli...I like the meat but not the eggs...We used to make sangrita with the eggs in a little glass"; "Love the eggs I do, but I can't get them"; "It's really rich - you can't eat plenty" (PN respondents) - though one PN respondent said that "I could make you a plate and you wouldn't know what it was: it looks the same as other meat". Another rationally self-interested reason for sea turtle egg poaching in Cahuita Town was that the perceived gains outweighed the potential risks [32]. "People don't have any pride because one turtle can bring in a lot of money" (CT respondent). The scarce availability of sea turtle eggs in Cahuita Town suggested that potential economic gain through sale of eggs was high, therefore making this illegal activity very appealing as a source of income. One respondent rationalised that "It is one of those reptiles that lays the most eggs on earth...Important for me to eat the eggs" (CT respondent). A Hone Creek respondent stated that "People collect the eggs and sell them...There isn't very much work here so it can be very important". Residents of Hone Creek and Playa Negra collect sea turtles eggs "through necessity" (HC respondent) because "there is no alternative work" (PN respondent). PN respondents said that "We eat it: catch it and eat it...It is important economically and as a food source... They sell some of it, some people...They get some money and buy something for the kids"; "I don't see anything wrong with it, because if you catch a fish it is good and they are a sea creature too... Things from the sea, I will always catch them and eat them"; "People don't use them for tourism here... We just use them to eat". In a confrontation with project staff, poachers stated that they would "take whatever they can get" when asked to restrict their behaviour to the beach located beyond national park boundaries (Personal communication, 2009). Another self-interested reason for non-compliance with protective regulations was the lack of alternative livelihood options. The international economic crisis had reduced the numbers of tourists: "there is less tourism so business is slow" (Personal communication, 2009), and increasing numbers of community members had to resort to sea turtle egg collection to maintain their families. Moreover, limited opportunity for involvement in the tourism industry meant widespread non-compliance with regulations. A key informant claimed that "in order to have the alternative livelihoods you need the support of both the management committee (of Cahuita Town) and MINAE...they're failing the ultimate goal of the park". However, truly rational self-interest dictated restraint in consumptive use: "Fishing with rationality"; "The act of fishing has to be done in a responsible way to make sure conservation... is effective"; so that "the people don't abuse the resources" (CT respondents); "If you do eat turtles and their eggs, you have to do it with care so that the planet isn't without turtles" (HC respondent). A PN respondent urged "It should be rationed, everything with caution", and another stated that they shared out or traded the eggs, rather than sold them: "People give them away...They'll collect the eggs and...give them away all around...People that come from San Jose want to commercialise it...People from outside buy it, but the natives don't.. We used to live a more subsistence lifestyle... We would exchange the eggs for some fish if you were a fisherman...More trading, not selling them... You could never sell them".

\subsection{Perception of governance effectiveness}

Respondents were asked about the need for, and effectiveness of, the Cahuita National Park. When asked if the park was necessary, respondents from Cahuita Town $(n=10)$ and Hone Creek $(n=19)$ were unanimous, with $100 \%$ stating that the rules are required, because "without the rules people would do what they want". The response in Playa Negra was significantly different (2-way Chi-Square, $\chi^{2}{ }_{35}=10.253$, d.f. $=2$, $p<0.05$ ), with $33.3 \%(n=6)$ believing that the restrictions were unnecessary. On the effectiveness of the national park, there was no difference in responses between communities, with $87.88 \%(\mathrm{n}=33)$ believing that it was effective. For example, a PN respondent declared that "There is plenty of protection for them here". Almost all respondents $(95.2 \%(n=21))$ stated that they thought the rules of the national park were fair, and $77.8 \%(n=18)$ considered enforcement of these rules to be fair. Respondents were asked to give their opinion of what sea turtle populations would be like if the national park had not been established. There was no significant difference in answers between the three communities. No respondent $(n=47)$ felt that sea turtle populations would be higher in the absence of the park, whereas $87.5 \%$ felt that sea turtle populations would have decreased. The prevailing view was that "everyone would just kill all the turtles". High levels of egg harvesting in beach locations beyond national park boundaries suggest that this would be a likely outcome. The minority who stated that sea turtle populations were unaffected by the establishment of the national park justified their answer by claiming that "there aren't any turtles here anyway so it wouldn't make very much difference". They also expressed worrying views about the lack of compliance with the Park's regulations. For example, CT respondents stated that there 
was "corruption" associated with the park, and to bypass the rules people "just have to have a friend in the government"; "people don't respect [the park] and they catch the turtles and other animals when they know it is illegal"; "they guard it during the day but not at night and that's when people go in there and steal things". Similarly, HC respondents claimed that conservation measures were failing, because - although "There is more protection than before"; "The government has created programs for the protection of the sea turtles"; "Now there are a lot of regulations"; "They have much more protection" - the fact is that "Now it is in danger of extinction... There used to be plenty of turtles but there aren't any more"; "There are hardly any turtles...If you go to the beach you don't see any" "They never used to take the eggs but now there are plenty of people who do take the eggs and turtles"; "Every day people are getting more greedy and taking more of them"; "people don't have any sense of limitations"; "People steal the eggs all the time so there are fewer than there used to be"; "Lots of the people around here go and steal the turtles and the eggs"; "people still go in the park during the night even though they're not supposed to". Likewise, PN respondents said that "Lots of people hunt animals here";"When I am hungry then I can go and find them"; "I don't see them anymore... Those big giant ones they used to catch aren't here...You only see those little ones now"; "I have lived here for 30 years...it used to be normal to see plenty of turtles coming up...Now it is just a little bit". However, one PN respondent claimed that the turtles had simply gone elsewhere: "They make a study and say that turtle is getting scarce... But I live here 57 years and I tell you it's not...Turtles is like sardines... They just change their space...They change where they're coming up...They run from here to somewhere else... The turtle travels the whole world".

\subsection{Prescriptions for the future}

Respondents were asked for their attitudes to their involvement in sea turtle conservation, and for their prescriptions for better protection of the animals in the study area. Willingness to become involved was widespread across all the communities, with $79.1 \%(n=43)$ stating they would like to participate in sea turtle conservation. However, expectations regarding the possibility of involvement differed significantly between communities (see Table 4). In Cahuita Town, respondents had lower expectations regarding involvement than did those in Hone Creek and Playa Negra. On prescriptions for better protection, $52.4 \%(\mathrm{n}=42)$ of respondents

\begin{tabular}{|c|c|c|c|}
\hline \multirow{2}{*}{ Community } & \multicolumn{3}{|c|}{ Would you expect to be invited to a meeting about sea turtles? (\%) } \\
\cline { 2 - 4 } & Yes & No & Maybe \\
\hline Cahuita $(\mathrm{n}=13)$ & 64.3 & 14.3 & 21.4 \\
\hline Hone Creek $(\mathrm{n}=23)$ & 91.3 & 8.7 & 0 \\
\hline Playa Negra $(\mathrm{n}=9)$ & 100 & 0 & 0 \\
\hline Statistics & \multicolumn{2}{|c|}{ 2-way Chi-Square, $\chi^{2}{ }_{45}=9.996$, d.f. $=4, \mathrm{p}<0.05$} \\
\hline
\end{tabular}

Table 4: Expectations of community members regarding possible invitations to meetings about sea turtles.

stated that they would like to see more protection and conservation of sea turtles, and $19.1 \%$ believed there should be increased education and awareness-raising in local communities. As one community member in Hone Creek commented, "sometimes we act badly through ignorance". On the future of sea turtles in the study area, $58.7 \%$ ( $n=46$ ) were optimistic, believing that numbers would increase, but $28.3 \%$ held that unless the manner in which sea turtles were used changed, numbers would decline.

\section{Discussion}

In this section we discuss the above results, analysing the different approaches to sea turtle conservation that were manifest in the three communities.

\subsection{Cahuita Town}

Cahuita Town $(\mathrm{CH})$ was the most dependent on tourism; it had the highest degree of social cohesion; and its residents showed the greatest awareness of the sea turtle conservation project in Cahuita National Park (CNP). Awareness of conservation efforts is known to be positively linked to compliant behaviour [34], and this is consistent with the results of this study. $\mathrm{CH}$ respondents expressed the highest number of norm-activated proenvironmental views (especially those based on ecological norms, legal norms, and cultural norms); the lowest number of norm-activated anti-environmental views; yet the lowest number of rational self-interested proenvironmental views; and the highest number of rational self-interested anti-environmental views. All $\mathrm{CH}$ respondents said that the CNP was necessary, and most said that its rules and their enforcement were effective 
and fair, though several respondents demurred, referring to extensive violation of the regulations. If, as suggested by Madrigal-Ballestero et al [35], legitimacy is positively linked to compliant behaviour, we would expect high compliance levels in $\mathrm{CT}$, which is what the results have shown. Although most $\mathrm{CH}$ respondents expressed willingness to become involved in sea turtle conservation, only two thirds thought they would be invited to do so.

\subsection{Hone Creek}

Hone Creek (HC) was based on mainly informal employment; it had a limited stock of social cohesion; and its residents had relatively little awareness of the sea turtle conservation project in Cahuita National Park. Nevertheless, HC respondents expressed the second highest number of norm-activated pro-environmental views (especially those based on personal norms, moral norms, and aesthetic norms); the second lowest number of norm-activated anti-environmental views; the highest (equal) number of rational self-interested proenvironmental views; and the lowest number of rational self-interested anti-environmental views. All HC respondents said that the CNP was necessary, but although most said that its rules and their enforcement were effective and fair, many complained of widespread poaching. Most HC respondents were willing to become involved in sea turtle conservation, and nearly all were optimistic that they would be given the opportunity.

\subsection{Playa Negra}

Playa Negra (PN) was also based mainly on informal employment; it had the lowest level of social cohesion; it had the lowest level of awareness of the sea turtle conservation project in Cahuita National Park. These low levels of social cohesion evidently reduced the amount of social pressure experienced by individuals, thus decreasing norm-activated behaviour and increasing rational choice behaviour. PN respondents expressed by far the lowest number of norm-activated pro-environmental views; the highest number of norm-activated antienvironmental views; the highest (equal) number of rational self-interested pro-environmental views; and the second highest number of rational self-interested anti-environmental views. Only two thirds of PN respondents said that the CNP was necessary, and many claimed that it had failed to prevent the turtles from disappearing. Most PN respondents were willing to become involved in sea turtle conservation, and all of them thought they would be invited to do so.

What emerges from this analysis is a complex and even paradoxical picture. On the face of it, Cahuita Town appeared to have a firmly embedded norm-based non-consumptive approach to sea turtle conservation resting on its high degree of social cohesion and well-established eco-tourist strategy, yet many of its respondents took a rational self-interested anti-environmental view, and detected some non-compliance with regulations. In the case of Hone Creek, where there was no tourism, and the vast majority of respondents said they were unaware of the sea turtle conservation project, nevertheless there were strongly held expressions of proenvironmentalism, both norm-based and rational self-interest based. As for Playa Negra, despite its lowest level of social cohesion and sea turtle conservation project awareness, it boasted the highest (equal) number of rational self-interested pro-environmental views.

The results show the applicability of the two main theories of compliant or pro-environmental behaviour - the norm-activation model (NAM) and the theory of planned behaviour (TPB) - as approaches to understanding the complex array of perceptions determining how communities favour consumptive versus non-consumptive use of sea turtles. However, we have found that NAM and TPB also explain non-compliant or anti-environmental behavioural, and that compliance and non-compliance with sea turtle conservation regulations are determined by a combination of normative and rational self-interested motives, both of which were identified in each of the three study communities. Another finding is that in times of hardship, as in Playa Negra, TPB explains more behaviour than does NAM, whereas in times of (relative) plenty, as in Cahuita Town where residents have the luxury of income generation through ecotourism, decisions regarding compliance with sea turtle regulations may be based on norms rather than solely on economic necessity. This finding accords with Maslow's theory of the 'hierarchy of needs' [36] - that basic physiological and security needs (food, shelter, employment and social stability) must be satisfied before those of self-esteem (respect for self and others) and self-actualisation (morality and culture) can be addressed.

\section{Conclusion}

In one respect, the results section corroborates the findings of previous studies [15] [37] that different communities have different perceptions about sea turtles and their conservation, reflecting the different circumstances facing them, and that managements must recognise these differences and allow communities to 
operate different regulations to manage their resources. However, the discussion section reveals a more complicated picture, showing that in each of the three communities there were respondents who held a wide range of views on sea turtle conservation, including norm-activated pro- and anti- environmentalism, and rationally self-interested pro- and anti- environmentalism. This suggest that managers of sea turtle conservation projects must respond to a variety of competing opinions within their own communities about their work, and be prepared to accommodate widely diverging views about the right protective measures to adopt. To so do, they may need to add negotiation and diplomatic skills to their scientific expertise in conservation.

\section{References}

[1] Tisdell C, Wilson C. Ecotourism for the survival of sea turtles and other wildlife. Biodiversity and Conservation 2002;11:1521-1538.

[2] IUCN 2012. The IUCN Red List of Threatened Species. Version 2012.2. <http://www.iucnredlist.org>. Downloaded on $14^{\text {th }}$ January 2013.

[3] Campbell LM. Ecotourism in rural developing communities. Annals of Tourism Research 1999;26(3): 534-553.

[4] Campbell LM. Science and sustainable use: views of marine turtle conservation experts. Ecological Applications 2002;12(4):1229-1246.

[5] Campbell LM. Conservation narratives in Costa Rica: conflict and co-existence. Development and Change 2002;33:29-36.

[6] Campbell LM. Local conservation practice and global discourse: a political ecology of sea turtle conservation. Annals of the Association of American Geographers 2007;97(2):313-334.

[7] Hope RA. Wildlife harvesting, conservation and poverty: the economics of olive ridley egg exploitation. Environmental Conservation 2002; 29(3):375-384.

[8] Reichart HA, Fretey J. Sea turtle recovery action plan for Suriname. CEP Technical Report No. 24.1993. UNEP Caribbean Environment Programme, Kingston, Jamaica.

[9] Jacobson SK, Robles R. Ecotourism, sustainable development, and conservation education: development of a tour guide training program in Tortuguero, Costa Rica. Environmental Management 1992;16(6):701-713.

[10] Jacobson SK, Lopez AF. Biological impacts of ecotourism: tourists and nesting turtles in Tortuguero National Park, Costa Rica. Wildlife Society Bulletin 1992;22(3):414-419.

[11] Scheyvens R. Ecotourism and the empowerment of local communities. Tourism and Management 1992; 20:245-249.

[12] Stronza A, Pêgas F. Ecotourism and Conservation: two cases from Brazil and Peru. Human Dimensions of Wildlife 2008;13:263-279.

[13] Wilson C, Tisdell C. Conservation and economic benefits of wildlife-based marine tourism: sea turtles and whales as case studies. Human Dimensions of Wildlife 2003;8:49-58.

[14] Ceballos-Lascurain H. Tourism, ecotourism and protected areas. Gland, Switzerland: IUCN; 1996.

[15] Campbell LM. Use them or lose them? Conservation and the consumptive use of marine turtle eggs at Ostional, Costa Rica. Environmental Conservation 1998;25(4):305-319.

[16] Bell S, Hampshire K, Topalidou S. The political culture of poaching: a case study from northern Greece. Biodiversity and Conservation 2007;16:399-418.

[17] Wood L. Motives for poaching in marine protected areas in the Seychelles. Western Indian Ocean Journal of Marine Science 2004;3(2):199-208.

[18] Bose S, Crees-Morris A. Stakeholder's views on fisheries compliance: An Australian case study. Marine Policy 2009;33(2):248-253.

[19] Hampshire K, Bell S, Wallace G, Stepukonis F. "Real" poachers and predators: shades of meaning in local understandings to threats of fisheries. Society and Natural Resources 2004;17(4):305-318.

[20] Jagers SC, Berlin D, Jentoft S. Why comply? Attitudes towards harvest regulations among Swedish fishers. Marine Policy 2012;36(5):969-976.

[21] Muth R, Bowe J. Illegal harvest of renewable natural resources in North America: towards a typology of the motivators for poaching. Society and Natural Resources 1998;15:17-31.

[22] Forsyth CJ, Gramling R, Wooddell G. The game of poaching: folk crimes in southwest Louisiana. Society and Natural Resources 1998;11:25-38.

[23] Bamberg S, Moser G. Twenty years after Hines, Hungerford, \& Tomera: a new meta-analysis of psycho-social determinants of pro-environmental behaviour. Journal of Environmental Psychology 2007; 27:14-25.

[24] Bamberg S, Hunecke M, Blobaum A. Social context, personal norms and the use of public transportation: two field studies. Journal of Environmental Psychology 2007;27:190-203.

[25] Schwartz SH. Normative influence on altruism. In Berkowitz L, editor. Advances in Experimental Psychology, Vol 10. New York: Academy Press; 1977:221-279. 
[26] Schwartz SH, Howard JA. (1981) A normative decision-making model of altruism. In Rushton, JP, Sorrentino, RM, editors. Altruism and helping behaviour. Hillsdale, NJ: Lawrence Erlbaum; 1981:89211.

[27] Stern PC. Towards a coherent theory of environmentally significant behaviour. Journal of Social Issues 2000; 56(3):407-424.

[28] Stern PC. Understanding individuals' environmentally significant behaviour. Environmental Law Reporter 2005; 35(11):10785-10790.

[29] Ajzen I. The theory of planned behaviour. Organizational Behavior and Human Decision Processes 1991;50:170-211.

[30] Weitzner V, Borrás MF. Cahuita, Límon, Costa Rica: From conflict to collaboration. In Buckles, D, editor. Cultivating peace: conflict and collaboration in natural resource management. Ottawa, Ontario: IDRC and World Bank Institute; 1999:129-150.

[31] Quesada-Rodriguez C, Chacón-Chaverri D. Volunteer Programs: A tool for conservation. In Rees, A.F., M. Frick, A. Panagopoulou and K. Williams, compilers. Proceedings of the Twenty-Seventh Annual Symposium on Sea Turtle Biology and Conservation. NOAA Technical Memorandum NMFS-SEFSC2007;569:104.

[32] Pauly D. Anecdotes and the shifting baseline syndrome of fisheries. Trends in Ecology and Evolution. 1995;10(10):430.

[33] Raakjer Nielsen J. An analytical framework for studying compliance and legitimacy in fisheries management. Marine Policy 2003;27:425-432.

[34] Senko J, Schneller AJ, Ollervides JSF, Nichols, WJ. People helping turtles, turtles helping people:Understanding resident attitudes towards sea turtle conservation and opportunities for enhanced community participation in Bahía Magdalena, Mexico. Ocean and Coastal Management 2011; 54:148-157.

[35] Madrigal-Ballestero R, Schluter A, Lopez, MC. What makes them follow the rules? Empirical evidence from turtle egg harvesters in Costa Rica. Marine Policy 2013;37:270-277.

[36] Maslow AH. Theory of human motivation. Psychological Review 1943; 50:370-396.

[37] Campbell L. M. Studying sea turtle conservation and learning about the world: Insights from social science. Conservation and Society 2010; 1(4): 1-4. 